\title{
Temptation and Self-Control: \\ Some Evidence from the Consumer Expenditure Survey*
}

\author{
Kevin X.D. Huang \\ Zheng Liu \\ Qi Zhu \\ Federal Reserve Bank of Philadelphia Emory University Emory University
}

January 2005

\begin{abstract}
This paper empirically estimates a balanced-growth consistent, dynamic, structural model of intertemporal consumption and asset pricing that allows for, but does not assume, the GulPesendorfer preferences of temptation and self-control, using synthetic panel data constructed from the Consumer Expenditure Survey. One novelty of our model is that the cross-sectional distribution of wealth-consumption ratio is a potentially important determinant for the implied pricing kernel, additional to the cross-sectional distribution of consumption growth, while the importance of this additional factor depends on the strength of temptation and self-control. The estimates that we obtain provide evidence supporting the existence of temptation and self-control in preferences. With reasonable precision, we estimate a significant present-biased temptation strength, and we reject the null hypothesis of no temptation at common confidence levels. We explore the quantitative implications of the self-control problems for equity premium, risk-free rate, and asset price volatility.
\end{abstract}

JEL classification: E44, C11, C15, G12

Key Words: Temptation; Self-control; Gul-Pesendorfer preferences; Asset pricing

${ }^{*}$ The views expressed herein are those of the authors and do not necessarily reflect the views of the Federal Reserve Bank of Philadelphia or the Federal Reserve System. 


\section{Introduction}

Experimental evidence suggests that time-orientation is a common occurrence in intertemporal decision-making. In the experiments, subjects reveal preference-reversals as time passes: they would choose the larger and later of two prizes when both are in a distant time, but they would prefer the smaller and earlier one as both prizes draw nearer to the present. A body of experimental studies which document the self-control problems that take the form of such short-run urges is surveyed by Rabin (1998), and heuristic psychological and sociological interpretations are also summarized in Loewenstein (1996). The idea that many consumers would have a lack of such self-control has also gained support in economics. The recent surveys by Ameriks, Caplin, Leahy, and Tyler (2004) over a sample of TIAA-CREF participants not only provides evidence of a lack of self-control among the survey participants, but indicates that self-control is linked to "conscientiousness", and the resulting propensity to consistent planning, a modeling approach which takes its root in Strotz (1956) and Peleg and Yaari (1973), and which gains an empirical support in the light of the surveys of TIAA-CREF participants by Ameriks, Caplin, Leahy (2003), and Ameriks, Caplin, Leahy (2002).

Standard economic models with preferences defined over actual consumption bundles and with exponential discounting do not allow for the observed preference-reversals and lack of self-control. Recent theoretical modelling that aims to tackle this problem takes two alternative approaches. The first approach addresses the preference-reversals using time-inconsistent preferences defined on the actual consumption [e.g., Laibson (1994, 1996, and 1997) and Harris and Laibson (2001)]. Here, dynamic inconsistency is introduced with hyperbolic or quasi-geometric discounting, while self-control is not allowed. ${ }^{1}$ The second and axiom-based approach addresses the problem by developing dynamically consistent preferences and utility representation over an extended domain, the set of choice problems that includes not only the actual consumption but what could have been consumed, namely, the temptation, in each period [e.g., Gul and Pesendorfer (2001, 2004b, and 2004c)]. This specification allows to capture the potential conflict between an agent's ex ante long-run ranking of options and his ex post short-run urges in a rational and time-consistent framework. The agent might be better-off if faced with a smaller opportunity set exclusive of the tempting elements a prior; otherwise, he might either succumb to the tempting alternatives or exercise costly self-control to refrain from choosing the tempting elements.

The time-consistent approach reconciles the many issues confronted by the time-inconsistent models. Its admissibility to recursive formulation of preferences and utility representation makes

\footnotetext{
${ }^{1}$ For some conceptual or practical issues concerning this time-inconsistent approach, see, for example, Jagannathan and Kocherlakota (1996), Rubinstein (2003), Gul and Pesendorfer (2004a), and Krusell and Smith (2003).
} 
its application particularly convenient. This is perhaps why it has gained an increasing popularity in applied work in various fields of economics since its original theoretical development a few years ago. ${ }^{2}$ However, the applied work has encountered a short supply of empirical evidence in quantifying the strength of temptation and self-control, or lack therefore, which is crucial for the assessment of the significance of their effects in the areas of greatest economic importance. ${ }^{3}$

The current paper represents our first pass in taking up on this empirical task. We investigate here the quantitative strength of temptation and self-control by empirically estimating, using the generalized method of moments, a dynamic structural model of intertemporal consumption and asset pricing that allows for, but does not assume, the Gul-Pesendorfer preferences. Hence, as to its primary goal, our present work is related to DeJong and Ripoll's (2003) paper estimating the temptation parameters in the Gul-Pesendorfer preferences by estimating a version of Lucas (1978) model of asset pricing. ${ }^{4}$ A main difference between our paper and theirs is that we use panel data constructed from the Consumer Expenditure Survey (CEX) in carrying out our empirical analysis while, in contrast, they base their empirical investigation on aggregate time series data. ${ }^{5}$

In this perspective, our work is perhaps more closely related to the papers by Paserman (2004), Fang and Silverman (2004), and Laibson, Repetto, and Tobacman (2004), who all employ panel or field data in estimating the quantitative effects of self-control problems under the specifications of hyperbolic time-preferences. ${ }^{6}$ Use of micro data is potentially important since time-orientation

\footnotetext{
${ }^{2}$ See, among others, Krusell, Kuruscu, and Smith (2002) and DeJong and Ripoll (2003) for application to asset pricing, Krusell, Kuruscu, and Smith (2003) to taxation, Ameriks, Caplin, Leahy, and Tyler (2004) to survey design, Gul and Pesendorfer (2004a and 2004b) to consumption-saving decision and welfare analysis, and Gul and Pesendorfer (2004d) to harmful addiction. Related theoretical and applied work also includes Benhabib and Bisin (2004), and Bernheim and and Rangel (2002), among others.

${ }^{3}$ Researchers have thus far largely calibrated models of preference-reversals to match some important moments of aggregate data sets. Among others, Laibson, Repetto, and Tobacman (1998) calibrate the hyperbolic discount factors in a model of saving for retirement, and Krusell, Kuruscu, and Smith (2002) calibrate a variant of the Gul and Pesendorfer model of asset pricing. Lack of direct empirical evidence on the quantitative strength of temptation and self-control makes difficult the quantitative evaluation of the importance of their effects. As Krusell et al. acknowledge, "Our results are hard to judge quantitatively since we do not have any independent information regarding the strength or nature of the possible savings urges among investors."

${ }^{4}$ The estimation by DeJong and Ripoll (2003) using the Bayesian method indicates the presence of a quantitatively significant temptation effect. But, these authors find that such effect, as they estimate based on aggregate data, does not fully account for the level of stock price volatility observed in U.S. data.

${ }^{5}$ In particular, DeJong and Ripoll (2003) use annual data on the $S \& P 500$ stock price and dividend series that Shiller (1981) used, extended through 1999.

${ }^{6}$ In estimating the degree of time-inconsistency in hyperbolic time-preferences, Passerman (2002) estimates a structural job search model using data on unemployment spells and accepted wages from the NLSY 1979, Fang and Silverman (2004) estimate a dynamic structural model of labor supply and welfare program participation using a single panel data on the choice of single women with dependent children from the NLSY 1979, and Laibson, Repetto,
} 
is argued to differ a lot among decision-makers and it is often deemed as essential to allow for individual differences in the degree of temptation and self-control. ${ }^{7}$ On a general level, preference heterogeneity and idiosyncratic risks may have significant effects in the areas of critical economic importance, such as consumption, saving, and asset pricing. For example, the importance for asset returns of idiosyncratic consumption risks, as relevant due to potential market incompleteness or limited asset market participation in particular, has been recently revisited by Brav, Constantinides, and Geczy (2002), Vissing-Jorgensen (2002), Cogley (2002), and Jacobs and Wang (2004) using the CEX data (see, also, the references therein for earlier and other contemporaneous studies based on the CEX and other data sources). Vissing-Jorgensen (2002) specifically emphasizes the implications of idiosyncratic risks and aggregation bias for consistent estimation of the elasticity of intertemporal substitution (EIS).

The main focus of the current paper is on joint estimation of EIS and the degree of temptation and self-control under a model specification that allows for the Gul-Pesendorfer preferences, using the CEX data which allow to deal with individual heterogeneity and aggregation issues to ensure consistent estimation and test overidentifying restrictions. The paper also explores the quantitative implications of the self-control problems for equity premium, risk-free rate, and asset price volatility. Our theoretical specification of the preferences and utility representation which are potentially of the Gul-Pesendorfer type is consistent with the balanced-growth property. Our empirical strategy is to focus on estimating a log-linear Euler equation, which is linear in parameters, based on data constructed for synthetic panels under various grouping criteria to control the aggregation process and to deal with measurement errors present in the individual data level in the absence of market completeness. This is fundamentally the same approach taken by VissingJorgensen (2002), among many other researchers, under the traditional preferences. ${ }^{8}$ Because of and Tobacman (2004) estimate a model of consumption and saving using field data on wealth accumulation, credit card borrowing, and consumption-income comovement. In particular, Laibson et al. calibrate some of their model parameters and estimate the discount factors using the method of simulated moments, and they reject the null of exponential discounting in most specifications.

${ }^{7}$ For instance, Della Vigna and Paserman (2004) present evidence on cross-sectional variation in the level of self-control and show that it predicts cross-sectional variation in behavior. Krusell, Kuruscu, and Smith (2002) argue for the realism of differing degree of temptation and self-control among consumers, and they demonstrate the potential significance of such heterogeneity in accounting for the high equity premium and low risk-free rate. Ameriks, Caplin, Leahy, and Tyler (2004) provide evidence on the heterogeneity in the degree of temptation and self-control and the importance for modelling it, based on a non-random sample of TIAA-CREF participants.

${ }^{8}$ The main advantages of such log-linear approach in a setting like the one in the current paper are demonstrated by Attanasio and Low (2004). Cogley (2002) and Jacobs and Wang (2004) consider pricing kernels that are linear in both the first- and the higher-order moments of the cross-sectional distribution of consumption growth. 
the allowance for the possibility of the Gul-Pesendorfer preferences in our specification, the crosssectional distribution of wealth-consumption ratio, in addition to the cross-sectional distribution of consumption growth, appears to become a potentially important determinant for the implied pricing kernel, while the importance of this additional factor depends on the strength of temptation and self-control. ${ }^{9}$ As a result, when applying the log-linear approach to our present setting, it is of critical importance to distinguish not only mean consumption growth from growth in mean consumption, but also mean wealth-consumption ratio from the ratio of mean wealth to mean consumption, in order to recognize the distinction between the case with incomplete markets and that with complete markets.

Our results are easily summarized. The estimates that we obtain provide evidence supporting the existence of temptation and self-control in preferences. With reasonable precision, we estimate a significant present-biased temptation strength, and we reject the null hypothesis of no temptation at common confidence levels. As a consequence, the mean wealth-consumption ratio becomes an empirically important factor for the determination of the resulting log-linear pricing kernel. We show analytically how temptation and self-control through the presence of this additional factor affect the pricing kernel, and we explore the quantitative implications of the self-control problems for some asset-pricing issues, such as equity premium and risk-free rate.

The remaining of the paper is organized in the following order. Section 2 presents a balancedgrowth consistent dynamic structural model of intertemporal consumption and asset pricing that allows for the Gul-Pesendorfer preferences of temptation and self-control. Section 3 describes our data source, discusses related issues on the measurement and definition of the key variables, classifies three alternative criteria for identifying asset holder status, and explains our sample selection criteria and synthetic cohort construction methods. Section 4 details our empirical method and estimation strategy. Section 5 reports our estimation results and offers some discussions. Section 6 reports our findings about the effects of temptation and self-control on equity premium, the Hansen-Jagannathan bound, and risk-free rate. Section 7 concludes the paper and points out some avenues for future research.

\section{A Consumption-Savings Model with Temptation and Self-Control}

In this section, we first consider an infinite-horizon consumption-savings problem that allows, but does not require, the possibility of temptation and self-control in preferences, as formalized by

\footnotetext{
${ }^{9}$ The importance of consumption-wealth ratio for asset pricing and evidence on the existence of a cointegration relationship between the variables based on aggregate time series data have already been demonstrated in the existing literature. See, among others, Lettau and Ludvigson (2001a, 2001b, and 2003).
} 
Gul and Pesendorfer (GP) (2001, 2004a, 2004b). We then characterize the stochastic discount factor (i.e., the asset pricing kernel) in the presence of temptation and dynamic self-control.

\subsection{An Axiom-Based Representation for Self-Control Preferences}

GP (2001, 2004b) consider decision problems by agents who are susceptible to temptations in the sense that ex ante inferior choice may tempt the decision-maker ex post. They develop an axiom-based, and thus time-consistent, representation of self-control preferences that identifies the decision-maker's commitment ranking, temptation ranking, and cost of self-control. According to their definition, "an agent has a preference for commitment if she strictly prefers a subset of alternatives to the set itself; she has self-control if she resists temptation and chooses an option with higher ex ante utility." They show that, to obtain a representation for the self-control preferences, it is necessary, on top of the usual axioms (completeness, transitivity, continuity, and independence), to introduce a new axiom called "set betweenness," which states that $A \succeq B$ implies $A \succeq A \cup B \succeq B$ for any choice sets $A$ and $B$. Under this axiom, an option that is not chosen ex post may affect the utility of the decision-maker because it causes temptation; and temptation is costly since an alternative that is not chosen cannot increase the decision-maker's utility.

Under these axioms, GP (2001) show that a representation for the self-control preferences takes the form

$$
W(A)=\max _{x \in A} u(x)+v(x)-\max _{y \in A} v(y)
$$

where both $u$ and $v$ are von Neumann-Morgenstern utility functions over lotteries and $W(A)$ is the utility representation of self-control preferences over the choice set $A$. The function $u$ describes the agent's ranking when she can avoid temptation through commitment, while the function $v$ describes the temptation facing the agent ex post. The term $\max _{y \in A} v(y)-v(x)$ is non-positive for all $x \in A$, and it represents the utility cost of self-control.

\subsection{The Infinite-Horizon Consumption-Savings Problem}

Consider now a consumption-savings problem in an infinite-horizon economy with a large number of households, idiosyncratic risks and incomplete insurance. Let $c_{t}^{h}$ denote consumption by household $h, e_{t}^{h}$ his endowment, and $b_{t}^{h}$ his wealth at the beginning of period $t$, where $h \in\{1,2, \ldots, N\}$. The households have access to an asset market, where they trade $I$ types of assets, in addition to a risk-free asset. Let $R_{t}^{i}$ denote the gross return of asset $i \in\{1, \ldots, I\}$ from period $t-1$ to $t$, and $R_{t}^{f}$ the risk-free rate. The households take the asset returns as given and choose consumption and new wealth positions to maximize their life-time discounted expected utility. In his decision 
problem, a household faces a temptation to consume all his wealth, and he may exert efforts to resist such temptations, and these efforts impose utility costs. GP (2004a) provides further axiomatic foundations for self-control preferences in an infinite-horizon economy with uncertainty, such as ours here. Following GP (2004a), we can formulate the decision problem for a generic household in a recursive way:

$$
W(b)=\max _{c \in(0, b]}\left\{u(c)+v(c)+\delta \mathrm{E} W\left(b^{\prime}\right)-v(b)\right\},
$$

where $u$ and $v$ are von Neumann-Morgenstern utility functions, $\delta \in[0,1]$ is a discount factor, and we have dropped the household index $h$ to keep the notations brief. The term $b^{\prime}$ denotes the wealth in the beginning of the next period and is given by

$$
b^{\prime}=e+R b-c .
$$

The first order necessary condition associated with the consumption-savings decision is then given by

$$
u^{\prime}\left(c_{t}\right)+v^{\prime}\left(c_{t}\right)=\delta \mathrm{E}_{t}\left[u^{\prime}\left(c_{t+1}+v^{\prime}\left(c_{t+1}\right)-v^{\prime}\left(w_{t+1}\right)\right] R_{t+1},\right.
$$

where $u^{\prime}(\cdot)$ and $v^{\prime}(\cdot)$ denote the marginal commitment utility and the marginal temptation utility, respectively, and $w_{t}=e_{t}+R_{t} b_{t}$ denotes the consumer's total wealth in the beginning of period $t$, that is, the maximum amount of resources that he can consume in period $t$ if he succumbs to temptation. The pricing kernel, or the stochastic discount factor (SDF), is here given by

$$
m_{t+1}=\frac{\delta\left[u^{\prime}\left(c_{t+1}+v^{\prime}\left(c_{t+1}\right)-v^{\prime}\left(w_{t+1}\right)\right]\right.}{u^{\prime}\left(c_{t}\right)+v^{\prime}\left(c_{t}\right)} .
$$

The consumption Euler equation (4) can then be rewritten as

$$
1=\mathrm{E}_{t} m_{t+1} R_{t+1}
$$

Our goal is to test the empirical importance of temptation and self-control in preferences. For this purpose, we restrict our attention to a class of CRRA utility functions, with the momentary and temptation utility functions given by

$$
u(c)=\frac{c^{1-\gamma}}{1-\gamma}, \quad, v(c)=\lambda u(c),
$$

where $\gamma$ is the coefficient of relative risk aversion and $\lambda>0$ measures the strength of temptation.

Under this specification of the utility functions, the SDF defined in (5) becomes

$$
m_{t+1}=\delta\left(\frac{c_{t+1}}{c_{t}}\right)^{-\gamma}\left[1-\frac{\lambda}{1+\lambda}\left(\frac{w_{t+1}}{c_{t+1}}\right)^{-\gamma}\right]
$$


Clearly, without temptation, that is, with $\lambda=0$, the SDF reduces to

$$
m_{t+1}=\delta\left(\frac{c_{t+1}}{c_{t}}\right)^{-\gamma}
$$

We are thus testing the hypothesis that the SDF is characterized by (8) against the alternative that it is described by (9). Or more explicitly, our null hypothesis is $\lambda=0$.

The extra term in the SDF in the presence of temptation is a function of the wealth-consumption ratio. Lettau and Ludvigson $(2001,2002)$ provide evidence that, in aggregate US data, wealth and consumption are cointegrated so that this ratio is stationary. We further assume that asset returns, consumption growth, and wealth-consumption ratio follow a jointly log-normal distribution. Under these assumptions, the consumption Euler equation (6) can be written as

$$
0=\mathrm{E}_{t}\left(\ln \left(m_{t+1}\right)+\ln \left(R_{t+1}\right)\right)+\frac{1}{2} \operatorname{Var}_{t}\left(\ln \left(m_{t+1}\right)+\ln \left(R_{t+1}\right)\right),
$$

where $\operatorname{Var}_{t}$ is a conditional variance operator.

In the absence of temptation, the utility function reduces to the standard CRRA form, with the SDF given by $\ln \left(m_{t+1}\right)=\ln (\delta)-\gamma \ln \left(c_{t+1} / c_{t}\right)$. In this case, equation (10) leads to an empirical version of the intertemporal Euler equation:

$$
\ln \left(\frac{c_{t+1}}{c_{t}}\right)=a_{0}+\sigma \ln \left(R_{t+1}\right)+\varepsilon_{t+1},
$$

where $\sigma=1 / \gamma$ is the elasticity of intertemporal substitution (EIS), the intercept term $a_{0}$ summarizes the constants and the unconditional mean of the second (or, in case of non-log-normal distributions, higher) moments of consumption growth and real asset returns, while the error term $\varepsilon_{t+1}$ contains expectation errors and the deviations of second (or higher) moments of consumption growth and asset returns from their unconditional means contained in $a_{0}$. This equation forms the basis for estimating the EIS (i.e., $\sigma$ ) in the literature [e.g., Attanasio and Weber (1989), Vissing-Jorgensen (2002)]. ${ }^{10}$

When temptation is allowed, the SDF takes the form as given by (8). Since all the variables involved in the SDF are assumed to be stationary, we can take a log-linear approximation to the SDF around steady state, with the resulting approximation given by

$$
\ln \left(m_{t+1}\right)=\ln (\delta)-\ln (1+\phi)-\gamma \ln \left(\frac{c_{t+1}}{c_{t}}\right)+\gamma \phi\left[\ln \left(\frac{w_{t+1}}{c_{t+1}}\right)-\ln \left(\frac{w}{c}\right)\right]+\kappa_{t+1},
$$

where the term $\kappa_{t+1}$ includes the second or higher moments in consumption growth and the wealth-consumption ratio, and the parameter $\phi$ is given by

$$
\phi=\frac{\lambda}{(1+\lambda) \chi^{\gamma}-\lambda},
$$

\footnotetext{
${ }^{10}$ See also the exchange between Caroll (2001) and Attanasio and Low (2004) about issues related to estimating log-linearized consumption Euler equations.
} 
with $\chi=w / c$ denoting the steady state ratio of wealth to consumption. Substituting this expression for the SDF into (10), we obtain an empirical version of the consumption Euler equation in the presence of temptation:

$$
\ln \left(\frac{c_{t+1}}{c_{t}}\right)=b_{0}+\sigma \ln \left(R_{t+1}\right)+\phi \ln \left(\frac{w_{t+1}}{c_{t+1}}\right)+\nu_{t+1},
$$

where the intercept term $b_{0}$ contains the constants and unconditional means of the second or higher moments of consumption growth, wealth-consumption ratio, and asset returns, and the error term $\nu_{t+1}$ summarizes expectation errors and the deviations of second or higher moments of the relevant variables from their unconditional means contained in $b_{0}$.

To test the empirical presence of temptation is thus equivalent to testing the Euler equation (14) under GP-preferences against its alternative (11) under CRRA utility. We implement this empirical task by first obtaining joint estimates of the EIS parameter given by $\sigma$ and the temptation parameter represented by $\lambda$ using GMM, and then test the null hypothesis that $\lambda=0$. To implement the GMM estimation, we use the log-linearized Euler equations (11) and (14) for the two alternative specifications of preferences, which, under rational expectations, imply the moment conditions $E_{t}\left(Z_{t} \varepsilon_{t+1}\right)=0$ for the standard CRRA utility and $E_{t}\left(Z_{t} \nu_{t+1}\right)=0$ for the GP preferences, for any vector of variables $Z_{t}$ that lie in the information set of period $t .{ }^{11}$ Note that, to obtain an estimate for $\lambda$ under GP preferences, we first estimate $\sigma$ and $\phi$ from (14), and then compute the point estimate of $\lambda$ from the relation

$$
\hat{\lambda}=\frac{\hat{\phi} \chi^{1 / \hat{\sigma}}}{1+\hat{\phi}\left(1-\chi^{1 / \hat{\sigma}}\right)},
$$

where a hatted variable denotes its point estimate. We then obtain a $95 \%$ confidence interval for the estimate of $\lambda$ using the delta method. The null hypothesis that $\lambda=0$ is equivalent to $\phi=0$.

\section{The Data}

In this section, we describe the data that we use to construct the variables used in estimating the intertemporal Euler equation. The source of the household-level data is the Consumer Expenditure Survey (CEX) produced by the Bureau of Labor Statistics (BLS). In what follows, we

\footnotetext{
${ }^{11}$ Although one cannot rule out the possibility that deviations of the conditional second or higher moments in the Euler equations from their unconditional means might be highly persistent, so that the use of lagged variables as instruments to estimate the Euler equations might be problematic in obtaining consistent estimates of the parameters of interest, Attanasio and Low (2004) show that, when utility is isoelastic and a sample covering a long time period is available, estimates from log-linearized Euler equation with varying interest rate are not systematically biased.
} 
first present a general overview of the CEX survey data (Section 3.1), discuss our procedure to construct a pseudo panel with synthetic cohorts of households (Section 3.2), and describe our sample selection criteria (Section 3.3). We then explain how to construct measures of consumption growth (Section 3.4), wealth-consumption ratio (Section 3.5), and asset returns (Section 3.6).

\subsection{Overview}

The CEX survey is conducted on an ongoing basis by the Bureau of Labor Statistics every quarter since 1980. It is a representative sample of the universe of U.S. households. In each quarter, BLS chooses randomly about 5000 households according to stratification criteria determined by the U.S. Census, asking them to report how much they spent on a variety of goods and services in the three prior months. The 5000 interviews are split more or less evenly over the three months of the quarter. Each household participates in the survey for five consecutive quarters, one training quarter with no data in record and four regular ones, during which expenditure, income, and demographic information is recorded. Financial information is gathered only in the last interview for both asset stocks at the time and flows over the last twelve months. In each quarter, new households replace roughly one fifth of the participating households, thus the CEX is a rotating panel covering a relatively long time period and containing considerable demographic information.

The survey attempts to account for about $95 \%$ of all quarterly household expenditures in each consumption category from a highly disaggregated list of consumption goods and services. This gives CEX data a main advantage over other micro-panel data, such as PSID, which reports expenditures for food only. CEX data would be particularly useful if preferences are nonseparable among different types of consumption goods and services in the theoretical model [e.g., Hall and Mishkin (1982), Zeldes (1989), Altug and Miller (1990), Cochrane (1991), Mankiw and Zeldes (1991), and Jacobs (1999)]. Further, as shown by Attanasio and Weber (1995), food consumption is a poor representative of consumption as a whole for investigations related to intertemporal substitution or asset pricing. For its broad coverage of consumption expenditures, CEX data have been widely used in the literature as an attractive alternative to aggregate macro data such as those in the Nation Income and Product Account (NIPA) to study a variety of issues such as inequality [e.g.,Deaton and Paxson (1994)], consumption smoothing [e.g., Attanasio and Weber (1995), Attanasio and Davis (1996), and Kruger and Fernandez-Vilaverde (2004)], and asset pricing [e.g., Vissing-Jorgensen (2002), Brav, Constantinides, and Gezcy (2002), Cogley (2002), and Jacobs and Wang (2004)]. 


\subsection{The Synthetic Cohorts}

The short panel dimension of the CEX makes the use of direct panel techniques problematic. Since each individual household is interviewed only 5 times (including a training period), we do not have any flexibility on the time-series dimension in estimating the Euler equation if we were to use individual household data. By exploiting the repeated nature of the CEX survey, Attanasio and Weber (1989, 1993, and 1995) proposed that one can build a pseudo-panel in the spirit of Browning, Deaton and Irish (1985), Deaton (1985), and Heckman and Robb (1985). As new households from a randomly selected large sample of the U.S. population keep entering the survey, consumption by the sampled households contains information about the mean consumption of the group to which they belong. Thus, a relatively long time series can be constructed for each cross sectional synthetic cohort (i.e., a typical group defined by observable characteristics), and this approach is know as the pseudo-panel technique.

We use the pseudo-panel technique to construct our synthetic cohorts based on the household head's birth year [see also Attanaio and Weber (1995 and 1998) and Krueger and FernandezVillaverde (2004)]. We define a birth-year cohort as a group of individuals who were born within a given five-year interval, and then follow them through the whole sample period to generate a balanced panel. We exclude from out sample those households whose heads were born after 1963 (younger than 21 in 1984) or before 1898 (older than 86 in 1984). The remaining households are assigned to thirteen cohorts (i.e., thirteen five-year intervals) based on their ages in 1984. We then further narrow down our sample by excluding those households whose heads are younger than 30 years in 1984 and those whose heads are older than 55 years in 1984, leaving five birth-year cohorts in our sample, with the household heads aged between 31 and 55 in 1984 and between 48 and 72 at the end of the sample (the beginning of 2002). The reason that we exclude those younger than 30 years is that these households have not had the chance to accumulate sufficient wealth and are thus likely to be liquidity constrained, so that the Euler equations may not hold; the reason that we exclude those older than 55 years is that households typically experience a discrete jump in consumption expenditures at the age of retirement, and it is not clear what causes such jump and whether or not the jump is consistent with the Euler equation. Those individuals who are older than 55 years in 1984 are likely to retire before the end of our sample in 2002, so we exclude them from the outset. ${ }^{12}$

We also report results obtained from data constructed using the simple cohort technique, an approach used by Vissing-Jorgensen (2002). Specifically, we pool the five birth-year cohorts

\footnotetext{
${ }^{12}$ For a survey of the literature that documents the jump in consumption at retirement age and attempts to explain the jump, see, for example, Attanasio (1999). See Laitner and Silverman (2004) for a more recent explanation.
} 
into a single large cohort, and compute the resulting cohort's consumption growth and wealthconsumption ratio by taking cross-sectional averages for each time period. This procedure results in a single time series.

\subsection{Limited Participation and Sample Selection Criteria}

The importance of limited asset market participation to consumption-based asset pricing model has been widely recognized in literature [e.g., Mankiw and Zeldes (1991), Weber (1999), Brav, Constantinides, and Geczy (2002), and Vissing-Jorgensen (2002) among others]. The main issue is that the consumption Euler equation holds only for interior optimizing decisions, that is, only for those households that are not financially constrained. Thus, to obtain sensible estimates of the EIS parameter and the temptation parameter based on the consumption Euler equation, we need to focus on households who do participate in financial market transactions.

In practice, we select a sub-sample of households who are classified as "asset holders" based on a similar set of criteria used by Cogley (2002) and Jacobs and Wang (2004). For a household's Euler equation between period $t$ and $t+1$ to hold, the household must hold financial assets in the beginning of period $t$, which corresponds to the beginning of the household's first interview in the CEX sample. For this reason, our first category of asset holders include those households who report positive holdings of "stocks, bonds, mutual funds, and other such securities" or "U.S. savings bonds" at the beginning of the first interview. ${ }^{13}$ Our second category of asset holders includes those households who report positive contributions to "an individual retirement plan, such as IRA or Keogh" during the first two interview quarters (i.e, during period $t$ ). Our final category includes those households who report receipts of positive dividend income or interest income during the first two interviews. Note that our classification of asset holders covers a broader sample than that used by Vissing-Jorgensen (2002), whose sample corresponds to our first category of asset holders. Based on these criteria, we categorize $42 \%$ of households as asset holders, which is comparable to that in Cogley (2002) (40\%) and in Haliassos and Bertaut (1995)

\footnotetext{
${ }^{13}$ We follow Vissing-Jorgensen (2002) in constructing this category of asset holders. Specifically, we use two pieces of information in the CEX survey: First, a typical household reports whether its holdings of the asset category remained the same, increased, or decreased, compared to a year ago; second, a typical household reports the difference in the estimated market value of the asset category held by the household in the last month with that held a year before. Thus, we infer that the household has a positive value of holdings of the asset category at the beginning of period $t$ if the household holds a positive amount of asset at the time of the interview and the asset value has either remained the same or decreased in the past year. If the household reports that an increase in the asset value and the amount of the increase does not exceed the holdings at the time of the interview, we also infer that the household has a positive holding of the asset category at the beginning of period $t$.
} 
(36.8\%), but somewhat higher than that in Jacobs and Wang (2004) (31\%) and in Mankiw and Zeldes (1991) (27.6\%), all of whom use a similar selection criterion but with a shorter sample in the time series dimension.

To minimize the influence of measurement errors and other problems caused by poor quality of the data in our estimation, we apply some further restrictions to our sample in constructing the consumption growth data. First, we drop from our sample those households who report nonpositive real quarterly consumption. Second, as in Zeldes (1989) and Vissing-Jorgensen (2002), we drop outliers in the data for consumption growth rates since these data may reflect reporting or coding errors. Third, we drop the households with any missing interviews, since we cannot compute semiannual consumption growth rate for these households. Fourth, we drop non-urban households, those residing in student housing, and those with incomplete income reports. Finally, we drop households that report a change in the age of the household head between any two interviews by more than one year or less than zero, so as to rule out the possibility of drastic changes in consumption behavior because of the change in household head. In addition, we note that, starting in interview period in the first quarter of 1986, the BLS changed its household identification numbering system, leaving no information about the correspondence between the household identification numbers in 1985:Q4 and 1986:Q1, so we have to drop some observations (7 monthly observations) related to this mismatching problem. A similar problem occurred again in 1996, and we have to drop another 4 monthly observations of consumption growth rate.

\subsection{The Consumption Growth Rate}

We follow a similar procedure as in Vissing-Jorgensen (2002) to construct consumption growth data using the CEX survey. ${ }^{14}$ We define consumption as the sum of expenditures on nondurable goods and services. We obtain a consumption basket for each household in the CEX survey by aggregating over various consumption categories reported in the survey to match the definition of nondurables and services in NIPA. A typical consumption basket includes food, alcoholic beverages, tobacco, apparel and services, gasoline and auto oil, household operations, utilities, public transportation, personal care, entertainment, and miscellaneous expenditures. By leaving out expenditures on durable goods, we implicitly assume that utility is separable in consumption of durables and of nondurables and services. We deflate nominal consumption expenditures by using the consumer price index for nondurables that is not adjusted for seasonality, with a base-period of 1982-1984. In addition to constructing consumption growth rate, we also need to construct

\footnotetext{
${ }^{14}$ A similar procedure is also used by, for instance, Anttanasio and Weber (1995), Cogley (2002), and Krueger and Fernandez-Vilaverde (2004).
} 
wealth-consumption ratio in order to estimate the Euler equation in the presence of temptation. The availability of household-level wealth data imposes restrictions on our choice of data frequency. In particular, we focus on the semiannual frequency. The semiannual consumption growth rate is defined as

$$
\frac{c_{m+6}^{h}+c_{m+7}^{h}+c_{m+8}^{h}+c_{m+9}^{h}+c_{m+10}^{h}+c_{m+11}^{h}}{c_{m}^{h}+c_{m+1}^{h}+c_{m+2}^{h}+c_{m+3}^{h}+c_{m+4}^{h}+c_{m+5}^{h}},
$$

where $m$ refers to the first month that a household makes its consumption decision, $m+3$ is the month that the first interview is conducted, when the household reports expenditures incurred during the prior three months (i.e., $c_{m}^{h}, c_{m+1}^{h}$, and $c_{m+2}^{h}$ ), $m+6$ is the month for the second interview when the household reports consumption expenditure for $m+3, m+4$, and $m+5$, and so on. ${ }^{15}$ Thus, for each household who has four complete interviews in record, we can obtain one observation of semiannual consumption growth rate. Yet, given the survey's rotating panel feature, we can construct a semiannual consumption growth rate for each month in a given synthetic cohort, which is the cross sectional average of the consumption growth rates for households in the same cohort. In particular, the average consumption growth rate for a specific cohort $j$ is obtained by

$$
\frac{1}{H_{t}^{j}} \sum_{h=1}^{H_{t}^{j}} \Delta \ln c_{t+1}^{h}=\frac{1}{H_{t}^{j}} \sum_{h=1}^{H_{t}^{j}} \ln \left(\frac{c_{t+1}^{h}}{c_{t}^{h}}\right),
$$

where $H_{t}^{j}$ denotes the number of households in cohort $j$ in period $t$. Note that, if complete insurance against idiosyncratic risks is available, then all households would have identical consumption, and the average consumption growth rate for a specific cohort described above would be identical to the growth rate of aggregate consumption per capita (such as that in the NIPA). In general, if there are uninsurable idiosyncratic risks, consumption would not be identical across households, so that our measure of consumption growth rate as described in (17) would be more appropriate than the one obtained from aggregate data.

Table 1 presents some summary statistics of our measure of semiannual consumption growth, sorted by asset holder status and cohort groups.

\subsection{The Wealth-Consumption Ratio}

To estimate the Euler equation (14) in the model that allows for temptation and self-control requires constructing data for not only the consumption growth rate, but also the wealth-consumption

\footnotetext{
${ }^{15}$ There is no direct data for monthly household-level consumption expenditures. But since the survey is conducted in a staggered fashion, we can construct a semiannual consumption growth rate for each month within the sample period.
} 
ratio. We now describe our procedure in constructing a measure for the wealth-consumption ratio that is consistent with theory.

In our model, a household's wealth in period $t$ is the maximum amount of resources available for consumption in that period if the household succumbs to temptation. It equals the sum of period$t$ labor income (or endowment) and the value of all financial assets available at the beginning of the period. In particular, for household $h$, his period- $t$ asset is given by $w_{t}^{h}=e_{t}^{h}+\sum_{i=1}^{I} R_{t}^{i} b_{t}^{i h}$, where, as discussed in Section 2, $e_{t}^{h}$ is the household's labor income (or endowment), $R_{t}^{i}$ is the gross return of asset $i$ from period $t-1$ to $t$, and $b_{t}^{i h}$ is household's holding of asset $i$ carried over from period $t-1$.

We are interested in obtaining the value of the household's asset holdings at the beginning of the decision period (corresponding to $b_{t}^{i h}$ in the model). Without loss of generality, we assume that the household's first decision period corresponds to the beginning of the first interview. ${ }^{16}$ The CEX survey does not provide household-level financial information for each interview; it does so only in the last interview. Fortunately, the survey provides us with both the asset holdings by each household at the end of the interview period and the asset flows for the same household during the past 12 months covering the entire interview period. We can thus retrieve the asset holdings at the beginning of the period $t$ by subtracting the change in asset flows during the entire interview period from the end-of-interview asset stocks. The value of the household's assets in the beginning of the first decision period can then be obtained by multiplying the asset holdings $b_{t}^{\text {ih }}$ by the asset's gross return $R_{t}^{i}$, and sum over asset categories $i$. The asset categories that we use in constructing the wealth data include liquid asset holdings in the household's "checking accounts, brokerage accounts, and other similar accounts," "saving accounts," "U.S. savings bonds," and "stocks, bonds, mutual funds, and other such securities." 17 To compute the total value of holdings of different types assets, we assume that a zero net return on the first category of assets (i.e., checking accounts, etc.); we use the 30-day Treasury bills returns as representing the returns on the second and the third category of assets (i.e., savings, and savings bonds); finally, we use the NYSE value-weighted returns as representing the returns for the last asset category (i.e., "stocks, bonds, mutual funds, and other such securities"). ${ }^{18}$

\footnotetext{
${ }^{16}$ In our semiannual data, each period corresponds to half a year. Thus, within the entire interview period (four quarters), the household has two decision periods: $t$ and $t+1$.

${ }^{17}$ We include here liquid assets only because the wealth in our model corresponds to the maximum amount of consumption if the household succumbs to temptation. The assets must have sufficient liquidity so that they can serve as "temptation."

${ }^{18}$ Clearly, we can obtain only one observation of asset value for each household during the entire interview period. But this does not present a problem for constructing our sample with semiannual data, since we can obtain only
} 
Upon obtaining the asset value for a household, we can get the household's wealth by adding up the household's asset value with its labor income earned in the decision period. The CEX survey reports, for each interview, the "amount of earned income after tax by household in the past 12 months." To calculate a household's semiannual labor income $e_{t}^{h}$ (i.e., income earned during the first half year of the household's interview period), we first divide the reported annual income at the time of each interview by four, and then add up the resulting quarterly incomes for the first and the second quarters in the interview period. Similarly, the income earned during the second half year of the household's interview period (i.e., $e_{t+1}^{h}$ ) is the sum of the household's average quarterly incomes for the third and the fourth interview quarters. Then, the household's wealth at the beginning of period $t$ is given by $w_{t}^{h}=e_{t}^{h}+\sum_{i}^{I} R_{t}^{i} b_{t}^{i h}$.

To get the wealth-consumption ratio for period $t$, we need further to construct the consumption data $c_{t}^{h}$ for household $h$ in period $t$. This is done by adding up the household's reported consumption expenditures during the first two interview quarters. ${ }^{19}$ The wealth-consumption ratio for household $h$ in period $t$ is then given by $w_{t}^{h} / c_{t}^{h}$, where both $w_{t}^{h}$ and $c_{t}^{h}$ are in nominal terms. Finally, we average across households in a given synthetic cohort $j$ to obtain a time series of the cohort's wealth-consumption ratio

$$
\chi_{t}^{j}=\frac{1}{H_{t}^{j}} \sum_{h=1}^{H_{t}^{j}} \frac{w_{t}^{h}}{c_{t}^{h}} .
$$

Note that, because of the rotating-panel feature of the CEX survey, we can construct the semiannual wealth-consumption ratio for each month within the sample period for a given cohort. Table 2 presents some summary statistics of the wealth-consumption ratio, sorted by asset holder status and birth-year cohorts.

\subsection{Asset Returns and Some Timing issues}

We use monthly NYSE value-weighted returns as a benchmark measure of nominal asset return and monthly 30-day Treasure bill returns as a measure of nominal risk-free returns. To calculate real returns, we use the consumer price index for urban households as a deflator. As discussed above, we are able to construct only one observation of consumption growth and of wealthconsumption ratio for each household at the semiannual frequency. Thus, we need to convert the monthly asset returns and risk-free returns into semiannual returns.

one observation of semiannual consumption growth rate for each household during the entire interview period, as discussed in Section 3.1, so we need only one observation for the wealth-consumption ratio for each household.

${ }^{19}$ In our estimation, the relevant wealth-consumption ratio in the Euler equation is for period $t+1$. So what we need is data for $w_{t+1}^{h}$ and $c_{t+1}^{h}$. To obtain $c_{t+1}^{h}$, we add up the household $h$ 's reported consumption expenditures during the last two interview quarters. 
To construct semiannual asset returns from monthly returns involves a somewhat tricky timing issue. As we explain in Section 3, the consumption growth data is computed as the ratio of a household's total consumption during the second half of the year in which the interview is conducted to its total consumption during the first half year (see (16)). The consumption-savings decision can be made in any month during the first half year. If the intertemporal consumptionsavings decision is between the first month and seventh month, then the relevant semiannual asset return should be $R_{m+1} R_{m+2} \cdots R_{m+6}$, where $R_{m+1}$ denotes the gross real asset return between month $m$ and $m+1, R_{m+2}$ is the return between month $m+1$ and $m+2$, and so on. But if the intertemporal decision occurs between the fourth and the tenth month, then the relevant semiannual return should be $R_{m+4} R_{m+2} \cdots R_{m+9}$. Our construction of the semiannual consumption growth data cannot distinguish between these two cases, thus we need to take a stand on what measure of the compounded returns is appropriate to serve our purpose of estimating the Euler equation. For simplicity and ease of comparison, we follow Vissing-Jorgensen (2002) and use the middle six months of relevant asset returns as a proxy the asset returns of interest. In particular, we use $R_{m+3} \cdots R_{m+8}$ as a measure of semiannual asset returns.

\section{Estimation Method}

We estimate the log-linearized conditional Euler equations of our model that allows for the GulPesendorfer preferences of temptation and self-control using the generalized methods of moments (GMM). We test the statistic significance of the temptation parameter by also estimating a restricted version of the model that does not allow for the temptation preferences and thereby constructing a Wald test statistic. In what follows, we describe in sequel the equations to be estimated, the instrumental variables to be used, and the estimation and testing procedure.

\subsection{The estimation equations}

The equation that we use in the estimation is a version of the log-linearized intertemporal Euler equation (14). In particular, the estimation equation for a particular cohort $j$ that consists of $H_{t}^{j}$ households in period $t$ is specified as

$$
\begin{gathered}
\frac{1}{H_{t}^{j}} \sum_{h=1}^{H_{t}^{j}} \Delta \ln c_{t+1}^{h}=\sigma \ln \left(R_{t+1}\right)+\phi \frac{1}{H_{t}^{j}} \sum_{h=1}^{H_{t}^{j}} \ln \left(\frac{w_{t+1}^{h}}{c_{t+1}^{h}}\right) \\
+\alpha \frac{1}{H_{t}^{j}} \sum_{h=1}^{H_{t}^{j}} \Delta \ln F_{t+1}^{j h}+\sum_{m=1}^{12} \delta_{m} D_{m}+\mu_{t+1}^{j}
\end{gathered}
$$


where $\sigma$ is the EIS, the $D$ 's are monthly dummies that are included for seasonal adjustment, and the cross-sectional average of log changes in the households' family size (denoted by $\Delta \ln F_{t+1}^{j h}$ ) is included as a sole control for demographics features that may potentially affect the marginal utility of consumption [see also Attanasio and Weber (1995) and Vissing-Jorgensen (2002)]. The coefficients in front of the monthly dummies, the $\delta$ 's, are functions of the subjective discount factor, the unconditional mean of the wealth-consumption ratio, and the conditional second or higher moments of the log asset returns, log consumption growth, and log wealth-consumption ratio. We use three alternative measures of asset returns (i.e., $R_{t+1}$ ): the real value-weighted NYSE returns, the real 30-day Treasury bill returns, and a joint return computed as the simple average between the first two measures.

The error term $\mu_{t+1}^{j}$ consists of expectation errors in the Euler equation and measurement errors in $\log$ consumption growth and $\log$ wealth-consumption ratio. It is also possible that the conditional second or higher moments contained in the $\delta$ 's are not constant, in which case, the $\delta$ terms captures the unconditional means of the second or higher moments terms, and the error term $\mu_{t+1}^{j}$ contains the deviations of these higher moments from their unconditional means. Even in this case, as long as variations in these higher moment terms are not correlated with the instruments that we are using, we can still obtain consistent estimates of the parameters of interest (i.e., $\gamma$ and $\phi$ ).

Even in the presence of measurement errors, one can still obtain consistent estimates of the EIS and the temptation parameter under some conditions. A sufficient condition is that the measurement errors in individual consumption and in wealth are multiplicative and proportional to each other (with a constant proportionality), and that they are independent of the true levels of consumption and wealth, independent of asset returns and of the instruments. ${ }^{20}$ Under these conditions, we can obtain consistent estimates of the EIS and the temptation parameter using the log-linearized Euler equation (19), with log consumption growth being a left-hand-side variable and with lagged consumption growth rates excluded from the set of instrumental variables.

In estimating the restricted version of our model that does not allow for the temptation preferences, we simply estimate (19) while imposing the restriction that $\phi=0$.

\subsection{Instrumental variables}

Under rational expectations, the expectation errors in $\mu_{t+1}$ are uncorrelated with any variables in the information set of period $t$. Let $Z_{t}$ denote a vector of variables in the period- $t$ information

\footnotetext{
${ }^{20}$ For a similar argument in the context of estimating EIS alone, see Attanasio and Weber (1995) and VissingJorgensen (2002).
} 
set. For simplicity, assume that the second or higher moment terms of the relevant variables in the estimation equation (19) are either constant or uncorrelated with $Z_{t}$. Then, in the absence of measurement errors, we have $\mathrm{E}_{t} Z_{t} \mu_{t+1}=0$, which are the moment conditions that we use in our estimation.

The instrumental variables that we use are a subset of the variables in $Z_{t}$. The instruments should be uncorrelated with the error term $\mu_{t+1}$ and correlated with the explanatory variables $R_{t+1}$ and $\ln w_{t+1} / c_{t+1}$. In addition to the monthly dummies and the changes in family size, we include in the set of instrumental variables (i) the log dividend-price ratio computed as the ratio of dividends paid during the previous 12 months to the current-period S\&P 500 index price, (ii) the lagged, log real value-weighted NYSE returns, and (iii) the lagged, log real 30-days Treasure bill return, all of which are known to be good predictors of real stock returns and Treasure bill returns. As such, they are likely to be correlated with the wealth-consumption ratio for asset holders. All these financial time series are downloaded from Center for Research of Security Prices. ${ }^{21}$

In our model, the decision period for an individual household is one half of a year, while the rotating-panel feature of the CEX survey implies that the time-series variables in the estimation equation (19) for a given cohort have monthly frequency. Thus, caution needs to be applied in constructing the lagged asset return data as instruments. Our construction of the semiannual consumption growth rates implies that consumption growth of a given cohort for adjacent months should have partially overlapping months and thus overlapping expectation errors. For this reason, the error term in log-linearized estimation equation (19) may be autocorrelated. To ensure that the instruments are uncorrelated with the error terms, we use the compounded return $R_{m-5} R_{m-4} \cdots R_{m}$ as the lagged asset returns in our set of instrumental variables, where the return in the latest month $R_{m}$ is the return for assets between period $m-1$ and $m$, so that the compounded, lagged, returns here are not correlated with the expectation errors that are relevant for the decision described by the Euler equation, despite of the overlapping nature of the errors.

\subsection{Estimation and Testing Procedure}

We use linear GMM estimation to obtain estimates of the EIS and the temptation parameter in (19), and explicitly account for autocorrelation of the MA(6) form and for heteroscedasticity of arbitrary forms in the error term. Autocorrelation in the error term may arise, as discussed above, from the overlapping nature of consumption growth and thus of expectation errors; and heteroscedasticity may present because of varying numbers of observations for each cohort cell

\footnotetext{
${ }^{21}$ We do not include lagged log consumption growth in the set of instrumental variables to avoid measurement error issues discussed above.
} 
over time. We use instrumental variables in the estimation to avoid inconsistent estimates of the parameters of interest because of possible endogeneity of asset returns and wealth-consumption ratio to expectation errors. We use the optimal weighting matrix in the GMM estimation.

In our estimation, we experiment with two different cohort techniques, the simple cohort approach used by Vissing-Jorgensen (2002) and the birth-year cohort approach proposed by Attanasio and Weber (1995). Under the simple-cohort technique, we obtain a single time series of consumption growth and of wealth-consumption ratio by taking the cross-sectional average of these variables at the household level across all households classified as asset holders. Under the birthyear cohort approach, we obtain a time series of consumption growth and wealth-consumption ratio for each birth-year cohort by taking cross-sectional averages across asset-holding households within each cohort. As discussed in Section 3.2, our birth-year cohorts consist of five-year intervals, and we focus on households whose heads are aged 30 to 54 years in 1984, so that we have five birth-year cohorts and thus five cohort-specific time series of consumption growth and of wealth-consumption ratio.

Our goal is to obtain consistent joint estimates of the EIS and the temptation parameter and test the statistical significance of the latter. Our estimation yields points estimates for the parameters $\sigma$ and $\phi$, but not $\lambda$ (the parameter measuring the strength of temptation), where $\phi$ is a nonlinear function of $\lambda, \sigma$, and the steady-state value of wealth-consumption ratio, as described by (13). We apply the Delta methods to calculate the point estimate of $\lambda$ and its $95 \%$ confidence interval using the estimates for $\sigma$ and $\phi$, as well as the time-series sample mean of the wealth-consumption ratio.

To test the statistical significance of the presence of temptation, we follow two steps. First, we estimate the unrestricted model given by (19). Second, we estimate a restricted model that imposes the restriction that $\phi=0$ (or equivalently, $\lambda=0$ ), that is, the standard Euler equation with CRRA utility. We then test the null hypothesis that $\phi=0$ using a Wald statistic obtained as the ratio of the minimized quadratic objective in the restricted model to that in the unrestricted model, adjusted by the sample size and the degree of freedom. The test statistic has a $\chi^{2}$ distribution with a degree of freedom equal to the number of restrictions (one restriction here).

\section{Results}

The results of the GMM estimations of the log-linearized model of equation (19) are shown in Table 3. The estimates of the parameters of interest are grouped by different synthetic cohort techniques, that is, simple cohort versus birth-year cohorts, as described in Section 4.3. In 
The first two columns (1a-1b) in Table 3 present the results from estimating the Euler equations with a single time series constructed by following the simple-cohort technique. ${ }^{22}$ To test the statistical significance of temptation, we estimate both the unrestricted model as described by (19) and a restricted model with $\lambda=0$ imposed, which corresponds to the standard model with CRRA utility, as in Vissing-Jorgensen (2002). Column (1a) reports the estimated value of the EIS in the restricted model, using value-weighted NYSE returns as a proxy for asset returns. The point estimate for EIS here is 0.271, very close to the value obtained by Vissing-Jorgensen (2002, Table 2) for stockholders (her estimate is 0.299). The point estimate of $\sigma$ as reported in Column (1a) is not statistically significant, although one cannot reject the overidentification restrictions based on Hansen's J-statistic. In the unrestricted model where we allow for temptation, the point estimate for $\sigma$ increases to 0.878 , and is still insignificant, with a standard error of 0.804 . The point estimate of $\phi$ is 0.04 , with a standard error of 0.043 . Similar to the restricted model, one cannot reject the overidentification restrictions based on the J-statistic. Yet, one cannot reject the null hypothesis that $\lambda=0$ based on the Wald-statistic with a p-value of 0.36 . In this case, the implied value of $\lambda$ is 0.87 , with a wide $95 \%$ confidence interval, as calculated using the Delta method. However, the rejection of the presence of temptation, as well as the inaccurate estimates of the EIS and the temptation parameter, may simply reflect the small sample size under the simple-cohort technique, which uses 199 observations in the estimation.

The synthetic cohort approach based on birth-year cohorts does not share this problem. Columns (2a-4b) report the estimates of the two alternative (unrestricted and restricted) models, using the pseudo-panel data constructed based on birth-year cohorts, with the three pairs of columns corresponding to the estimation results using three different proxies of asset returns. Each pseudo panel consists of five time-series, corresponding to the five birth-year cohorts. The sample size is now 988 , close to five times as much as that under the simple-cohort technique. ${ }^{23}$

Columns (2a-2b) report the estimation and testing results using the value-weighted NYSE returns as a proxy for asset returns. The point estimates of the EIS here are similar to those

\footnotetext{
${ }^{22}$ Each time series has 199 monthly observations, covering the sample from October 1983 to March 2001, where 11 monthly observations are missing because of the mismatching problem in the identification numbering system in 1986 and 1996. Note that, the earliest interview period is the first quarter of 1984, when the households report consumption expenditures in the past three months, so that we can construct a cohort-specific consumption growth series that starts in October 1983. The last interview period in our sample is the first quarter of 2002. Since a household's intertemporal consumption-savings decision shifts consumption between the first half year and the second half during the interview period, we need a whole year's consumption data to construct a consumption growth rate for a given household, so that the last available consumption growth data ends by March 2001.

${ }^{23}$ In the pseudo panel, some birth-year cohort cells are empty, so that the total number of observations in the panel is slightly less than five times that under the simple-cohort approach.
} 
obtained using the simple-cohort technique, which use the same proxy for asset returns but with a single time series rather than a panel of data. The main difference here is that, in the unrestricted model, the estimates of both the EIS and the temptation parameter are now statistically significant at the $5 \%$ and $10 \%$ levels, respectively, and that the Wald-statistic and the associated p-value indicate strong rejection of the null hypothesis that $\lambda=0$, providing statistical support for presence of temptation and self-control. The point estimate of the EIS is $\sigma=0.98$, with a standard error of 0.496 ; the point estimate of $\phi$ is 0.055 , with a standard error of 0.029 . This information, coupled with the fact that the sample-mean of the wealth-consumption ratio is $\bar{\chi}=9.31$, implies that $\lambda=1.05$, with a $95 \%$ confidence interval between -2.93 and 5.02. As in the case with a simple cohort, the J-statistic here cannot reject the overidentification restrictions in the model that allows for temptation. Unlike the previous case, however, the J-statistic here does indicate rejection of the overidentification restrictions in the model with the standard CRRA utility.

To examine the robustness of the results, we also estimate and test the models using some other proxies for asset returns. Columns (3a-3b) report the results when we replace the stock returns by the risk-free returns measured by the returns on 30-day Treasury bills. The estimates of the EIS in both models are now greater than unity and notably larger than those obtained using stock returns. They are both significant at the $95 \%$ level. ${ }^{24}$ The point estimate for $\phi$ is now 0.025 , with a standard error of 0.015 , somewhat smaller and less significant than in the case when stock returns are used. The implied value for $\lambda$ is 0.05 , with a $95 \%$ confidence interval between -0.02 and 0.13 . The Hansen's J-statistic fails to reject the overidentification restrictions in each model. As in the case with stock returns, the Wald-statistic and the associated p-value indicate strong rejection of the null that $\lambda=0$, suggesting the presence of temptation and self-control.

Finally, in Columns (4a-4b), we implement a joint estimation by combining stock return and risk free Treasury bill return in one regression. The asset return is here a simple average of stock returns and Treasury bill returns. The estimated values of the EIS in the two alternative models lie somewhere between those obtained from stock returns data (Column 2) and those from riskfree returns data (Column 3). The Wald-test of model restrictions strongly rejects the null that $\lambda=0$ (with a p-value of $4 \%$ ). The point estimate of $\lambda$ is now 0.26 with $95 \%$ confidence interval between -0.08 and 0.59 . The presence of temptation and self-control is again evident.

\footnotetext{
${ }^{24}$ This result is similar to that obtained by Vissing-Jorgensen (2002).
} 


\section{Some Applications in Asset Pricing}

We now examine some quantitative implications of temptation and self-control utility for some asset-pricing issues, such as equity premium and risk-free rate.

\subsection{Equity Premium and the Hansen-Jaganathan Bound}

Let $R_{t}^{f}$ denote the gross return of a risk-free asset between period $t$ and $t+1$, and $R_{t+1}^{e}=R_{t+1}-R_{t}^{f}$ the excess return. It is straightforward to show that the risk-free return equals the inverse of the conditional mean of the SDF. That is,

$$
R_{t}^{f}=\frac{1}{E_{t}\left(m_{t+1}\right)}
$$

Using this relation and the intertemporal Euler equation (6), we obtain the unconditional mean of the excess return

$$
\mathrm{E}\left(R^{e}\right)=-\frac{\operatorname{Cov}\left(m, R^{e}\right)}{\mathrm{E}(m)} .
$$

Let $\rho\left(m, R^{e}\right)$ denote the correlation coefficient between the SDF and the excess return, and $\sigma(x)$ denote the standard deviation of a variable $x$. Using the relations that $\operatorname{Cov}\left(m, R^{e}\right)=$ $\sigma(m) \sigma\left(R^{e}\right) \rho\left(m, R^{e}\right)$ and the fact that $\rho\left(m, R^{e}\right) \leq 1$, we obtain from (21) the Hansen-Jagannathan (HJ) bound

$$
\frac{\left|E\left(R^{e}\right)\right|}{\sigma\left(R^{e}\right)} \leq \frac{\sigma(m)}{E(m)} \approx \sigma(\ln m),
$$

where the last approximation follows from the assumption of log-normal distribution of the SDF. Using (12), we obtain

$$
\frac{\left|E\left(R^{e}\right)\right|}{\sigma\left(R^{e}\right)} \leq \frac{\sigma(m)}{E(m)} \approx \sqrt{\sigma^{2}(\ln m)}=\gamma \sqrt{\sigma^{2}\left(\Delta \ln c_{t+1}\right)+\phi \Gamma},
$$

where $\Delta \ln c_{t+1}=\ln \left(c_{t+1} / c_{t}\right)$ denotes the log-growth rate of consumption, and the term $\Gamma$ is given by

$$
\Gamma=\sigma\left(\ln \chi_{t+1}\right)\left[\phi \sigma\left(\ln \chi_{t+1}\right)-2 \sigma\left(\Delta \ln c_{t+1}\right) \rho\left(\Delta \ln c_{t+1}, \ln \chi_{t+1}\right)\right],
$$

where $\chi_{t+1}=w_{t+1} / c_{t+1}$ denotes the wealth-consumption ratio.

Clearly, without temptation and self-control, $\phi=0$ so that $\sigma(\ln m)=\gamma \sigma\left(\Delta \ln c_{t+1}\right)$ and the HJ-bound takes the standard form

$$
\frac{\left|E\left(R^{e}\right)\right|}{\sigma\left(R^{e}\right)} \leq \frac{\sigma(m)}{E(m)} \approx \gamma \sigma\left(\Delta \ln c_{t+1}\right) .
$$

In the US data, average excess return is about 0.8 percent and the standard deviation of the excess return is about 0.16 percent, so that the sharp ratio is about $\frac{\left|E\left(R^{e}\right)\right|}{\sigma\left(R^{e}\right)}=0.5$ (see, for example, Cochrane (2005)). Since the standard deviation of consumption growth in aggregate US 
data is around 0.01 percent, the HJ bound requires a risk-aversion of an implausible magnitude: $\gamma$ has to be greater than or equal to 50 ! This illustrates a version of the equity premium puzzle first presented by Mehra and Prescott (1985).

A natural question is then: Does introducing temptation and self-control in the utility function help resolve the equity premium puzzle? Comparing the HJ bound under the GP preferences (23) and the one under the standard CRRA utility (25), we see that the answer depends on the sign and magnitude of the term $\phi \Gamma$, where $\Gamma$ is given by (24). As long as consumption growth and the wealth-consumption ratio are negatively correlated, we would have $\Gamma>0$ and things would be moving to the right direction. Indeed, in our sample of households who hold assets in the CEX data, the correlation coefficient between consumption growth and wealth-consumption ratio is about -0.09 , so that $\Gamma>0$. Now, what about the magnitude? To see how large the temptation parameter $\phi$ should be to help resolve the equity premium puzzle, we first fix the risk aversion parameter at $\gamma=1$, which is close to its point estimate in the presence of temptation, as reported in Table 5 (column $2 \mathrm{~b}$ ). We then use the sample standard deviation of consumption growth given by $\sigma(\Delta \ln c)=0.04$, the standard deviation of logged wealth-consumption ratio given by $\sigma(\ln \chi)=0.39$, and a sample correlation of $\rho(\Delta \ln c, \ln \chi)=-0.09$ between these two variables to compute a lower bound for $\phi$ so that the HJ bound in (23) is satisfied, that is, $\gamma \sqrt{\operatorname{var}\left(\Delta \ln c_{t+1}\right)+\phi \Gamma} \geq 0.5$. It turns out that to satisfy the HJ bound requires $\phi>1.26$. In contrast, the largest point estimate for $\phi$ is no larger than 0.06 , roughly two orders of magnitude lower than that required to satisfy the HJ bound! Thus, although the strength of temptation is empirically significant, allowing for temptation and self-control in utility does not help explain the equity premium puzzle.

\subsection{The Risk-Free Rate}

A related puzzle in the asset-pricing literature is why the observed risk-free rate is much lower than the theoretical predictions. The risk-free return is related to the SDF through (20), which, under the assumption of log-normal distributions, lead to

$$
r_{t}^{f}=-\ln \delta+\ln (1+\phi)+\gamma \mathrm{E}_{t} \Delta \ln c_{t+1}-\phi \gamma \mathrm{E}_{t}\left(\ln \chi_{t+1}-\ln \chi\right)-\frac{\gamma^{2}}{2}\left[\operatorname{var}_{t}\left(\Delta \ln c_{t+1}\right)+\phi \Gamma_{t}\right],
$$

where $r_{t}^{f}=\ln R_{t}^{f}$, and we have used the log-linear approximation to the SDF as in (12). Here, the term $\Gamma_{t}$ takes a similar form as in (24), with conditional moments in place of the unconditional moments. The presence of temptation (i.e., with $\phi>0$ ) has an ambiguous effect on the risk-free rate. A larger value of $\phi$ tends to increase the risk-free rate through the constant term $\ln (1+\phi)$; meanwhile, it tends to lower the risk-free rate through the additional second-moment term $\phi \Gamma_{t}$, 
which, as we show above, is positive in our sample. Within an empirically plausible range of the temptation parameter values, the overall effect on the risk-free rate is likely small. Thus, allowing for temptation and self-control in utility does not help explain the risk-free rate puzzle either.

\section{Conclusion}

In a series of important contributions, Gul and Pesendorfer (2001, 2004a, 2004b) have laid down a theoretical, axiomatic, foundation for the representation of preferences that allows for temptation and self-control. One of the main attractions of the axiomatic approach is that such preference representation is time-consistent, and is thus suitable to be used to study optimal policies that are designed to maximize a well-defined social welfare objective. Temptation and self-control preferences have many important implications on macroeconomic issues such as social security reform, income tax reform, and a variety of asset-pricing issues [e.g., Krusell and Smith (2003), Krusell, et al. (2002, 2003), DeJong and Ripoll (2003), and the survey by Gul and Pesendorfer (2004b)]. To assess with confidence the quantitative importance of such preferences for these prominent issues, one wants to first get a sense of whether the presence of temptation and selfcontrol in preferences is supported by individual household-level data.

This paper provides a first attempt to estimate the strength of temptation and self-control using household-level data. We have presented a simple infinite-horizon consumption-savings model that allows, but does not require, temptation and self-control in preferences. We have shown that, in the presence of temptation and self-control, the stochastic discount factor (i.e., the assetpricing kernel) is a function of not only consumption growth, as in standard models with CRRA utility, but also wealth-consumption ratio. We show that this is a feature unique to our model with temptation and self-control preferences. Using individual household-level data on consumption and wealth from the U.S. Consumer Expenditure Survey, we have obtained statistically significant joint estimates of the elasticity of intertemporal substitution and the parameter measuring the strength of temptation and self-control. Our aggregation procedure in constructing the data for estimating these parameters of interest allows for the possibility of uninsurable idiosyncratic shocks, and our empirical results lend support to the presence of temptation and self-control in individuals' preferences.

The theoretical results and empirical estimations presented in this paper suggest that the wealth-consumption ratio along with the consumption growth for asset holders, as broadly defined, should jointly determine the asset-pricing kernel. As a preliminary application of our results, we have examined here the implications of allowing for temptation and self-control in preferences for 
several asset-pricing issues, such as those on the equity premium, the Hansen-Jagannathan bound, and the risk-free rate, and we found that the effects of our estimated, statistically significant strength in temptation and self-control on these asset pricing anomalies are not quantitatively very significant. Notwithstanding these findings, our results imply more directly that the wealthconsumption ratio for asset holders may serve as a pricing or conditioning factor in helping forecast future asset returns or explain the cross-section of asset returns. In a sense, aggregate wealthconsumption ratio has already been identified in the previous research as a useful conditioning variable within the context of the consumption-based capital asset pricing model (CCAPM) to account for the cross-section of asset returns [e.g., Lettau and Ludvigson (2001a, 2001b, 2004)]. Yet, the wealth-consumption ratio as at the aggregate level has been found to lack out-of-sample forecasting power in predicting future assets returns [see, for example, the exchange between Lettau and Ludvigson (2002) and Brennan and Xia (2002). See, also, Avramov (2002)]. Various statistical reasons, such as the lack of enough time-series observations, have been proposed to explain the lack of out-of-sample forecasting power of this theoretically justified factor. A natural next step for future research is to explore the power in predicting asset returns of the wealthconsumption ratio at the individual level for asset holders who are subject to temptation and self-control, based on micro-level data, such as the pseudo-panel data constructed here from the CEX. In addition to addressing directly the sample-size problem confronted by the aggregate time series data, this proposed avenue for future research allows to capture, at least in part, the effects of market incompleteness and uninsurable idiosyncratic shocks along with temptation and self-control in preferences, which may be of critical importance for testing power.

Needless to say, one can also investigate the quantitative importance of temptation and selfcontrol for many other important economic issues, including various issues in public finance, such as those associated with social security reform that has been catching much attention lately. Doing so would certainly require a reliable empirical assessment of the strength of temptation and self-control in preferences. Our work represents a first step toward this direction.

\section{References}

Altug, Sumru, and Robert A. Miller, 1990, Household Choices in Equilibrium. Econometrica 58, 543-570.

Ameriks, John, Andrew Caplin, and John Leahy, 2002, Retirement Consumption: Insight from a Survey. NBER Working Paper No. 8735. 
Ameriks, John, Andrew Caplin, and John Leahy, 2003, Wealth Accumulation and the Propensity to Plan. Quarterly Journal of Economics 118, 1007-1047.

Ameriks, John, Andrew Caplin, John Leahy, and Tom Tyler, 2004, Measuring Self-Control. NBER Working Paper No. W10514.

Attanasio, Orazio P., and Guglielmo Weber, 1989, Intertemporal Substitution, Risk Aversion and Euler Equation for Consumption. The Economic Journal 99, Supplement: Conference Papers 59-73.

Attanasio, Orasio P., and Guglielmo Weber, 1993, Consumption Growth, the Interest Rate and Aggregation. Review of Economic Studies 60, 631-649.

Attanasio, Orazio P., and Hamish Low, 2004, Estimating Euler Equations. Review of Economic Dynamics 7, 406-435.

Attanasio, Orazio P., and Guglielmo Weber, 1995, Is Consumption Growth Consistent with Intertemporal Optimization? Evidence from the Consumer Expenditure Survey. Journal of Political Economy 103, 1121-1157.

Attanasio, Orazio P., and Steven J. Davis, 1996, Relative Wage Movements and the Distribution of Consumption. Journal of Political Economy 104, 1227-1262.

Attanasio, Orazio P., 1998, Cohort Analysis of Saving Behavior by U.S. Households. The Journal of Human Resources 33, 575-609.

Attanasio, Orazio P., 1999, Consumption. Chapter 11 of Handbook of Macroeconomics, Vol 1, J.B. Taylor and M. Woodford (ed), Elsevier Science B.V. 1999.

Avramov, Doron, 2002, Stock return predictability and model uncertainty, Journal of Financial Economics 64, 423-458.

Benhabib, Jess, and Alberto Bisin, 2004, Modelling Internal Commitment Mechanisms and SelfControl: A Neuroeconomic Approach to Consumption-Saving Decisions. Working Paper, New York University.

Bernheim, B. Douglas, and Antonio Rangel, 2002, Addiction and Cue-Conditioned Cognitive Processes. NBER Working Paper No.9329.

Brennan, Michael J. and Yihong Xia, 2002, Tay's as good as cay, Working paper, UCLA and University of Pennsylvania.

Brav, Alon, George Constantinides, and Christopher Geczy, 2002, Asset Pricing with Heterogeneous Consumers and Limited Participation: Empirical Evidence. Journal of Political Economy 110, 793-824.

Browning, Martin, Angus Deaton, and Margaret Irish, 1985, A Profitable Approach to Labor Supply and Commodity Demands over the Life-Cycle. Econometrica 53, 503-543. 
Cochrane, John H., 1991, A Simple Test of Consumption Insurance. Journal of Political Economy 99, 957-976.

Cochrane, John H., 2005, Asset Pricing. Princeton University Press.

Cogley, Timothy, 2002, Idiosyncratic Risk and the Equity Premium: Evidence from the Consumer Expenditure Survey. Journal of Monetary Economics 49, 309-334.

Deaton, Angus, 1985, Panel Data from Time Series of Cross-Sections. Journal of Econometrics 30, 109-126.

Deaton, Angus, and Christina Paxson, 1994, Intertemporal Choice and Inequality. Journal of Political Economy 102, 437-467.

DeJong, David, and Marla Ripoll, 2003, Self-Control Preferences and the Volatility of Stock Prices. Working Paper, University of Pittsburgh.

Della Vigna, Stefano, and M. Daniele Paserman, 2004, Job Search and Impatience. Working Paper, University of California, Berkeley.

Fang, Hanming, and Dan Silverman, 2004, Time Inconsistency and Welfare Program Participation: Evidence from the NLSY. Cowles Foundation Discussion Paper No. 1465, Yale University.

Gul, Faruk, and Wolfgang Pesendorfer, 2001, Temptation and Self-Control. Econometrica 69, 1403-1436.

Gul, Faruk, and Wolfgang Pesendorfer, 2004a, Self-Control and the Theory of Consumption. Econometrica 72, 119-158.

Gul, Faruk, and Wolfgang Pesendorfer, 2004b, Self-Control, Revealed Preference and Consumption Choice. Review of Economic Dynamics 7, 243-264.

Gul, Faruk, and Wolfgang Pesendorfer, 2004c, The Revealed Preference Theory of Changing Tasts. Review of Economic Studies (forthcoming).

Gul, Faruk, and Wolfgang Pesendorfer, 2004d, Harmful Addiction. Review of Economic Studies (forthcoming).

Harris, Christopher, and David Laibson, 2001, Dynamic Choices of Hyperbolic Consumers. Econometrica 69, 935-957.

Hall, E. Robert, and Frederic Mishkin, 1982, The Sensitivity of Consumption to Transitory Income: Estimate from Panel Data on Households. Econometrica 50, 461-481.

Heckman, James.J., and Richard Robb, 1985, Alternative Methods for Evaluating the Impact of Interventions. in James.J. Heckman and Burton Singer (eds), Longitudinal Analysis of Labor Market Data. Cambridge University Press.

Jacobs, Kris, 1999, Incomplete Markets and Security Prices: Do Asset-Pricing Puzzles Results from Aggregation Problems? Journal of Finance 54, 123-164. 
Jacobs, Kris, and Kevin Q. Wang, 2004, Idiosyncratic Consumption Risk and the Cross Section of Asset Returns. Journal of Finance 59, 2211-2252.

Jagannathan, Ravi, and Narayana R. Kocherlakota, 1996, Why Should Older People Invest Less in Stocks Than Younger People? Federal Reserve Bank of Minneapolis Quarterly Review 20(3), $11-23$.

Krueger, Dirk, and Jesus Fernandez-Villaverde, 2004, Consumption over the Life Cycle: Facts from Consumer Expenditure Survey Data. Working Paper, University of Pennsylvania.

Krusell, Per, and Anthony A. Smith, 2003, Consumption-Savings Decision with Quasi-Geometric Discounting. Econometrica 71, 365-375.

Krusell, Per, Burhanettin Kuruscu, and Anthony A. Smith, 2002, Time Orientation and Asset Prices. Journal of Monetary Economics 49, 107-135.

Krusell, Per, Burhanettin Kuruscu, and Anthony A. Smith, 2003, Temptation and Taxation. Working Paper, Yale University.

Laibson, David, 1994, Self-Control and Savings. Ph.D dissertation, MIT.

Laibson, David, 1996, Hyperbolic Discounting, Undersaving, and Savings Policy. NBER Working Paper No. 5635.

Laibson, David, 1997, Golden Eggs and Hyperbolic Discounting. Quarterly Journal of Economics $112,443-477$.

Laibson, David I., Andrea Repetto, and Jeremy Tobacman, 1998, Self-Control and Saving for Retirement. Brookings Papers on Economic Activity 0, 91-172.

Laibson, David I., Andrea Repetto, and Jeremy Tobacman, 2004, Estimating Discount Functions from Lifecycle Consumption Choices. Working Paper, Harvard University.

Laitner, John, and Dan Silverman, 2004, Estimating Life-Cycle Parameters from the RetirementConsumption Puzzle. Working Paper, University of Michigan.

Lettau, Martin, and Sydney Ludvigson, 2001a, Consumption, Aggregate Wealth, and Expected Stock Returns. Journal of Finance 56, 815-849

Lettau, Martin, and Sydney Ludvigson, 2001b, Resurrecting the (C)CAPM: A Cross-Sectional Test When Risk Premia are Time-Varying. Journal of Political Economy 109, 1238-1287.

Lettau, Martin, and Sydney Ludvigson, 2002, Tay's as good as cay: reply, Working paper, Department of Economics, New York University.

Lettau, Martin, and Sydney Ludvigson, 2004, Understanding Trend and Cycle in Asset Values: Reevaluating the Wealth Effect on Consumption. American Economic Review 94, 276-299.

Loewenstein, George, 1996, Out of Control: Visceral Influences on Behavior. Organizational Behavior and Human Decision Processes 65, 272-292. 
Lucas, Robert J., 1978, Asset Prices in an Exchange Economy. Econometrica 46, 1429-1445.

Mankiw, N. Gregory, and Stephen P. Zeldes, 1991, The Consumption of Stockholders and Nonstockholders. Journal of Financial Economics 29, 97-112.

Mehra, Rajnish, and Prescott, Edward C., 1985, The Equity Premium: A Puzzle. Journal of Monetary Economics 15(2), 145161.

Paserman, Daniele, 2004, Job Search and Hyperbolic Discounting: Structural Estimation and Policy Evaluation. Working Paper, Hebrew University.

Peleg, Bezalel, and Manahem E. Yaari, 1973, On the Existence of a Consistent Course of Action when Tastes are Changing. Review of Economic Studies 40, 391-401.

Rabin, Matthew, 1998, Psychology and economics. Journal of Economic Literature 36, 11-36.

Rubinstein, Ariel, 2003, "Economics and Psychology"? The Case of Hyperbolic Discounting. International Economic Review 44, 1207-1216.

Shiller, Robert J., 1981, Do Stock Prices Move Too Much to be Justified by Subsequent Changes in Dividends? American Economic Review 71, 421-436.

Strotz, R.H., 1956, Myopia and Inconsistency in Dynamic Utility Maximization. Review of Economic Studies 23, 165-180.

Vissing-jorgensen, Annette, 2002, Limited Asset market Participation and the Elasticity of Intertemporal Substitution. Journal of Political Economy 110, 825-853.

Zeldes, Stephen P., 1989, Consumption and Liquidity Constraints: An Empirical Investigation. Journal of Political Economy 97, 305-346. 
Table 1.

Summary Statistics for Consumption Growth

\begin{tabular}{|c|c|c|c|c|c|c|c|c|c|}
\hline & No. Obs & Mean & S.D. & Skew. & Kurt. & Min & $\operatorname{Max}$ & $1 \%$ & $99 \%$ \\
\hline \multicolumn{10}{|c|}{ Panel A: Individual Consumption Growth } \\
\hline ALL & 19060 & 0.010 & 0.305 & -0.017 & 5.240 & -1.575 & 1.605 & -0.805 & 0.825 \\
\hline Asset Holder & 8116 & 0.010 & 0.308 & -0.060 & 5.346 & -1.575 & 1.605 & -0.808 & 0.834 \\
\hline \multicolumn{10}{|c|}{ Panel B: Consumption Growth for Simple Cohort (single time series) } \\
\hline ALL & 199 & 0.010 & 0.044 & -0.097 & 3.140 & -0.109 & 0.123 & -0.093 & 0.115 \\
\hline Asset Holder & 199 & 0.011 & 0.061 & -0.214 & 2.732 & -0.157 & 0.143 & -0.147 & 0.137 \\
\hline \multicolumn{10}{|c|}{ Panel C: Birth-Year Cohort, 1949 - 1953} \\
\hline ALL & 199 & 0.012 & 0.063 & -0.014 & 2.664 & -0.163 & 0.172 & -0.140 & 0.150 \\
\hline Asset Holder & 199 & 0.011 & 0.093 & -0.054 & 3.295 & -0.266 & 0.247 & -0.245 & 0.244 \\
\hline \multicolumn{10}{|c|}{ Panel D: Birth-Year Cohort, 1944 - 1948} \\
\hline ALL & 199 & 0.008 & 0.070 & 0.249 & 2.925 & -0.153 & 0.222 & -0.119 & 0.209 \\
\hline Asset Holder & 199 & 0.013 & 0.100 & -0.323 & 3.926 & -0.408 & 0.252 & -0.201 & 0.242 \\
\hline \multicolumn{10}{|c|}{ Panel E: Birth-Year Cohort, 1939 - 1943} \\
\hline ALL & 199 & 0.007 & 0.081 & -0.057 & 2.947 & -0.217 & 0.217 & -0.204 & 0.199 \\
\hline Asset Holder & 199 & 0.019 & 0.130 & -0.089 & 4.090 & -0.465 & 0.469 & -0.318 & 0.328 \\
\hline \multicolumn{10}{|c|}{ Panel F: Birth-Year Cohort, $1934-1938$} \\
\hline ALL & 199 & 0.009 & 0.094 & 0.595 & 5.747 & -0.299 & 0.479 & -0.211 & 0.236 \\
\hline Asset Holder & 193 & 0.011 & 0.138 & 0.820 & 6.856 & -0.387 & 0.751 & -0.308 & 0.449 \\
\hline \multicolumn{10}{|c|}{ Panel G: Birth-Year Cohort, 1929 - 1933} \\
\hline ALL & 199 & 0.008 & 0.099 & -0.188 & 3.512 & -0.368 & 0.256 & -0.252 & 0.237 \\
\hline Asset Holder & 198 & 0.005 & 0.155 & -0.267 & 4.267 & -0.522 & 0.465 & -0.467 & 0.464 \\
\hline \multicolumn{10}{|c|}{ Panel H: Consumption Growth for All Birth-Year Cohorts (pooled synthetic panel) } \\
\hline ALL & 995 & 0.009 & 0.082 & 0.121 & 4.433 & -0.368 & 0.479 & -0.190 & 0.216 \\
\hline Asset Holder & 988 & 0.012 & 0.125 & 0.041 & 5.461 & -0.522 & 0.751 & -0.319 & 0.315 \\
\hline
\end{tabular}


Table 2.

Summary Statistics for Wealth-Consumption Ratio

\begin{tabular}{|c|c|c|c|c|c|c|c|c|c|}
\hline & No. Obs & Mean & S.D. & Skew. & Kurt. & Min & $\operatorname{Max}$ & $1 \%$ & $99 \%$ \\
\hline \multicolumn{10}{|c|}{ Panel A: Individual Wealth-Consumption Ratio } \\
\hline ALL & 19060 & 5.596 & 11.84 & 14.87 & 433.5 & -146.5 & 501.2 & 0 & 46.76 \\
\hline Asset Holder & 8116 & 9.021 & 17.09 & 10.96 & 225.7 & -146.5 & 501.2 & 0 & 74.50 \\
\hline \multicolumn{10}{|c|}{ Panel B: Wealth-Consumption Ratio for Simple Cohort (single time series) } \\
\hline ALL & 199 & 5.732 & 2.110 & 2.048 & 8.601 & 3.143 & 16.78 & 3.215 & 15.15 \\
\hline Asset Holder & 199 & 8.933 & 4.351 & 1.619 & 5.475 & 4.233 & 27.16 & 4.381 & 24.06 \\
\hline \multicolumn{10}{|c|}{ Panel C: Birth-Year Cohort, 1949 - 1953} \\
\hline ALL & 199 & 5.407 & 3.134 & 3.977 & 25.34 & 2.438 & 29.62 & 2.10 & 21.25 \\
\hline Asset Holder & 199 & 8.192 & 6.428 & 4.059 & 25.71 & 2.233 & 58.53 & 2.041 & 39.03 \\
\hline \multicolumn{10}{|c|}{ Panel D: Birth-Year Cohort, $1944-1948$} \\
\hline ALL & 199 & 5.544 & 2.561 & 2.396 & 11.33 & 2.397 & 20.14 & 2.772 & 17.58 \\
\hline Asset Holder & 199 & 8.420 & 5.442 & 2.378 & 10.11 & 0.236 & 34.09 & 1.651 & 27.00 \\
\hline \multicolumn{10}{|c|}{ Panel E: Birth-Year Cohort, 1939 - 1943} \\
\hline ALL & 199 & 5.914 & 3.683 & 4.190 & 32.80 & 2.494 & 38.46 & 2.575 & 16.33 \\
\hline Asset Holder & 199 & 9.397 & 8.558 & 4.472 & 30.70 & 2.945 & 77.74 & 3.231 & 36.54 \\
\hline \multicolumn{10}{|c|}{ Panel F: Birth-Year Cohort, $1934-1938$} \\
\hline ALL & 199 & 5.849 & 3.765 & 2.787 & 12.98 & 0.889 & 26.50 & 1.006 & 25.15 \\
\hline Asset Holder & 193 & 10.26 & 9.777 & 3.310 & 15.57 & 1.322 & 69.09 & 1.901 & 51.70 \\
\hline \multicolumn{10}{|c|}{ Panel G: Birth-Year Cohort, 1929 - 1933} \\
\hline ALL & 199 & 6.446 & 8.065 & 10.16 & 125.1 & 0.625 & 107.4 & 1.017 & 24.44 \\
\hline Asset Holder & 198 & 11.53 & 12.47 & 5.044 & 34.89 & 0.449 & 107.4 & 1.333 & 63.35 \\
\hline \multicolumn{10}{|c|}{ Panel H: Wealth-Consumption Ratio for All Birth-Year Cohorts (pooled synthetic panel) } \\
\hline ALL & 995 & 5.832 & 4.677 & 11.57 & 229.6 & 0.625 & 107.4 & 1.567 & 20.65 \\
\hline Asset Holder & 988 & 9.312 & 8.950 & 4.978 & 39.77 & 0.236 & 107.4 & 2.190 & 51.70 \\
\hline
\end{tabular}


Table 3 .

GMM Estimation of Log-Linearized Euler Equations

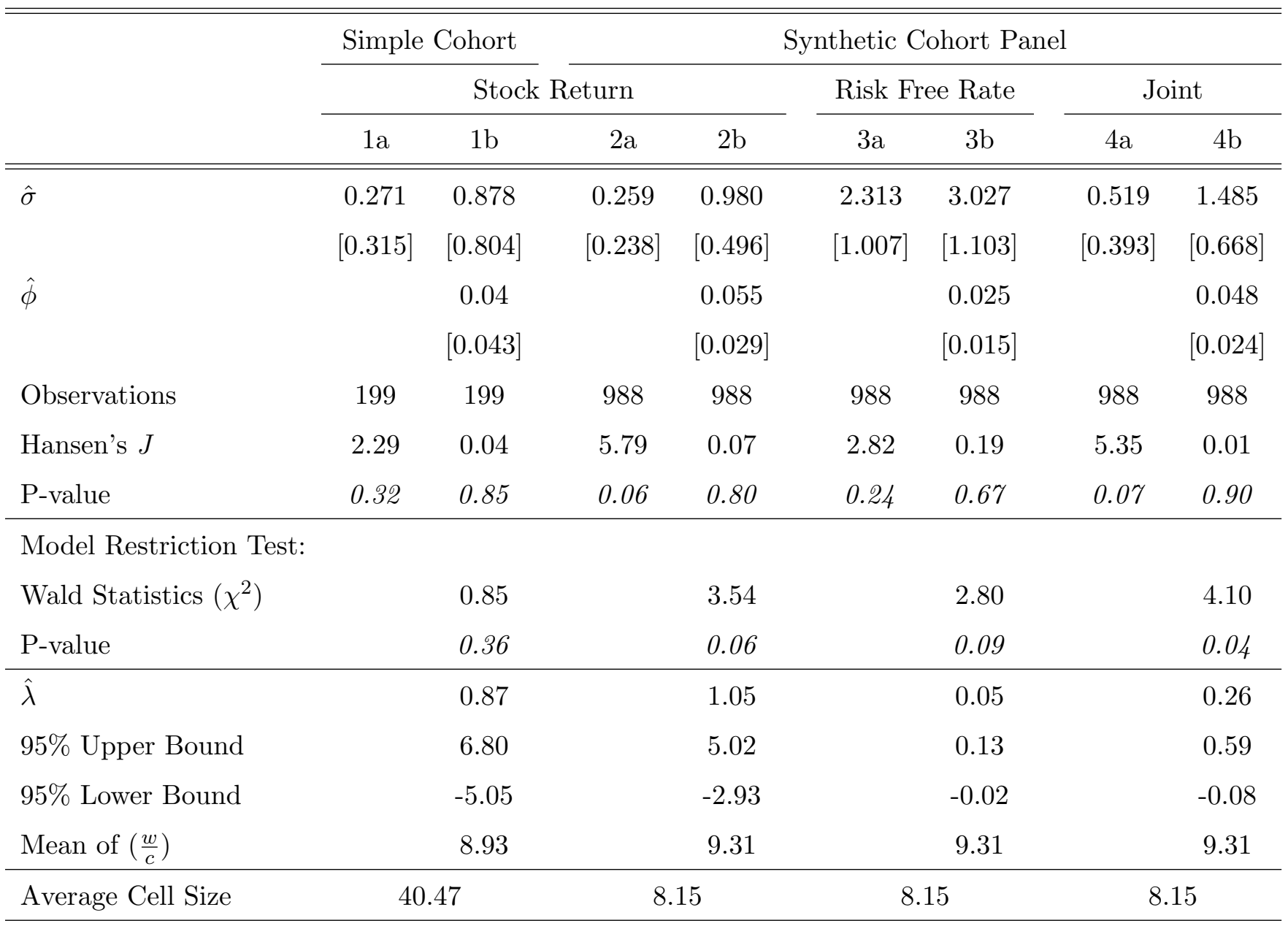

Note: Robust standard errors in brackets. The regressions also include $\Delta \ln ($ familysize $)$ and twelve monthly dummies as explanatory variables and instruments. The instrument set for asset return and wealth-consumption ratio also includes log dvidend-price ratio, lagged log real value weighted NYSE returns, and lagged log real 30-day Treasury bill returns. The Hansen's $J$ statistic for overidentification test follows a $\chi^{2}$ distribution with 2 degrees of freedom in the restricted model (with CRRA utility) and 1 degree of freedom in the unrestricted model (with temptation utility). The null hypothesis for the model restriction test is that $\phi=0$ (or equivalently, $\lambda=0$ ). The Wald statistic for the restriction test has a $\chi^{2}$ distribution with 1 degree of freedom. The $95 \%$ bounds for $\hat{\lambda}$ is calculated using the "Delta method." 